Dossiê

\title{
APRESENTAÇÃO \\ DOSSIÊ QUESTÃO AMBIENTAL E MOVIMENTOS SOCIOAMBIENTAIS
}

\author{
Prof. Dr. Sérgio Botton Barcellos \\ Bolsista PNPD-CAPES e Professor no PPGS-UFPEL
}

Prof. Dr. Everton Lazaretti Picolotto Professor do Departamento de Ciências Sociais e do Programa de Pós-Graduação de Ciências Sociais da UFSM

A questão ambiental e os conflitos ambientais são centrais nas sociedades contemporâneas, têm dado base para a emergência de novos movimentos sociais com contorno ecológicos (Touraine, 2007; Castells, 2002), ao mesmo tempo em que têm fomentado outras formas de olhar para o conhecimento técnico-científico, para o desenvolvimento socioeconômico e para os sentidos da modernidade (Beck, 1992; Giddens, 1991; 1997; Habermas, 1987, 2012).

As ciências sociais estão sendo chamadas para dar respostas para alguns problemas que ligam o mundo social e o seu ambiente. Estas questões toram-se cada vez mais candentes em um mundo em que as consequências da ação humana predatória alimentam conflitos de recorte socioambiental nos planos internacional e local, envolvendo desde povos e comunidades tradicionais (áreas indígenas, quilombolas, comunidades ribeirinhas, pescadores, caiçaras, etc), agricultores familiares, pescadores artesanais, povos das florestas, até as grandes corporações industriais e comerciais, o sistema financeiro e os Estados.

De outra parte, é no mundo social que se torna possível a produção e a reprodução das condições de existência humana a partir de sua relação com a natureza, pelo conjunto de ações sociais que por meio dos "seres humanos se apropriam, produzem, circulam, transformam, consomem e excretam materiais e/ou energias provenientes do mundo natural" 
(Casado; Sevilla-Guzmán; Molina, 2000, p. 87). É pertinente considerar a necessidade de buscar a compreensão da questão ambiental à luz de temáticas como o desenvolvimento industrial, civilização moderna, políticas públicas e recursos naturais, mas também sob um prisma socioambiental. Isso significa compreender a unidade entre as relações sociais inerentes à natureza - história - sociedade.

O "ambientalismo" ou a "questão ecológica" emerge a partir da década de 1960, abarcando e mobilizando distintos segmentos sociais, constituindo o que pode ser entendido como movimentos "socioambientais". Estes movimentos não se centram apenas em torno da estrutura, conflitos e interesses de classes das sociedades capitalistas, mas também nas relações entre o homem e a natureza, o meio-ambiente construído, as condições gerais de produção e a provisão de bens públicos. Desta forma, a questão ambiental tem alimentando a emergência de novos atores (em distintas escalas), reinvindicações e necessidades de ações dos Estados. Embasados nesta problemática têm se constituído uma miríade de movimentos socioambientais, com demandas e orientações político-ideológicas diversas sobre o atual modelo de desenvolvimento socioambiental e de exploração dos recursos naturais.

A repercussão do movimento ambientalista e ecologista para trazer à tona a Sociologia Ambiental, tanto como objeto de estudo, como o envolvimento com a temática ambiental por meio do engajamento pessoal de alguns sociólogos trouxe diversas formas de problematização sobre a relação sociedade-natureza e os impactos resultantes da expansão econômica e a percepção humana sobre os impactos e dilemas ecológicos nas nações industriais avançadas (BUTTEL, 1992).

Ao mesmo tempo, nesse cenário relativo aos movimentos com pautas socioambientais e povos com modos de vida intrinsicamente vinculados à questão ambiental, em meio a disputas e conflitos em torno da ocupação e acesso a terra no Brasil (Reforma Agrária), têm passado por determinadas mudanças e ampliações tanto no seu repertório de pautas, quanto no seu formato de organização política. Observa-se que essas pautas estão relacionadas a pautas socioambientais, como desenvolvimento rural sustentável, preservação ambiental, à defesa da biodiversidade, culturas locais e a agroecologia.

Cabe ainda considerar, que recentemente a região do Rio Doce em Minas Gerais foi cenário de uma das maiores catástrofes ambientais da nossa história com o rompimento da barragem da Samarco, lançando sobre o rio cerca de 50 milhões de $\mathrm{m}^{3}$ de rejeito de mineração. A lama com rejeitos atingiu diversas comunidades e avança sobre o Rio Doce causando 
impactos socioambientais sem precedentes no Brasil, como falta de água e inviabilizando a pesca, em 15 municípios de Minas Gerais e do Espírito Santo até desaguar no Oceano Atlântico, onde também causa danos ainda imprevisíveis em sua intensidade e extensão.

Diante disso, um Dossiê sobre a temática ambiental em uma Revista Acadêmica mostra-se muito pertinente em uma conjuntura de desastres ambientais e de diversos conflitos e até guerras civis ocorrem tendo como pano de fundo a disputa por território e recursos naturais como combustíveis fósseis (como no Oriente Médio), recursos hídricos, minério e até flora e fauna por biopirataria. No Brasil temos diversos conflitos envolvendo a disputa pela terra com famílias e povos indígenas com casos de homicídio, denúncias constantes de infrações ambientais cometidas por empresas do agronegócio e de mineração.

Sob essa perspectiva, esse trabalho conta com a participação de 16 pesquisadores (as) de diversas universidades do Brasil e de universidades da Argentina e do Chile, além da entrevista de um agricultor militante no tema da agricultura de base ecológica, com temáticas e objetos de pesquisa diversos sobre a questão ambiental e abarcando os movimentos e organizações socioambientais em relação a contextos variados, como obras de usinas hidrelétricas e megaempreendimentos; o contexto rural em assentamentos rurais; o espaço urbano e suas atuais transformações socioambientais; o debate sobre os povos e comunidades tradicionais; e o impacto dos agrotóxicos em nossas vidas.

$\mathrm{O}$ artigo As questões socioambientais como um campo de disputas simbólicas: os debates sobre a construção da usina hidrelétrica de Mauá, de Rafael Braz problematiza como determinadas correntes teóricas podem dialogar com determinadas questões socioambientais empíricas. Trata especialmente aquelas nas quais os debates são muito recorrentes e as possibilidades de acordo, como no caso de instalação de Usinas Hidrelétricas, e pelo qual abordou as discussões sociológicas e ecológicas em meio às controvérsias socioambientais desse tipo de empreendimento.

Camila Dellagnese Prates, no artigo Tecnologia e Ambiente: As escolhas técnicas e seus efeitos "sociais" aborda as transformações ambientais e os efeitos "sociais" que resultam da inserção de um artefato tecnocientífico na a construção da Usina Hidrelétrica de Belo Monte (UHEBM), situada nas proximidades de Altamira no Pará, amparada nas incursões teóricas da Sociologia da Ciência e da Tecnologia. O empírico (os estudos altimétricos que delimitam a cota 100) foi realizado no estado do Pará. Este trabalho contribui para pensar sobre a atuação do MPF como um ator que formata uma controvérsia tecnocientífica, a 
mantém aberta e promove diferenciações na compreensão dos impactos e subsequentes modificações nesse ambiente.

Em Distâncias e proximidades na lógica da desigualdade ambiental, Caio Floriano dos Santos e Rafaela Silva Dornelas discutem o tema da desigualdade ambiental a partir dos elementos que nos trazem dois casos de conflitos: o imprensamento das comunidades quilombolas do Sapê do Norte, no estado do ES, pelas monoculturas de eucalipto da Fibria, antiga Aracruz Celulose; e o sufocamento das comunidades do SuperPorto (Vila Mangueira, Barra Nova e Barra) pela modernização portuária, indústria naval e de fertilizantes no município de Rio Grande/RS (extremo sul do Brasil), constituindo-se como zonas de sacrifício. A proposta de reunir dois casos de empreendimentos de natureza distintas e em localidades distantes parte da inquietação quanto à repetição da lógica de implantação de grandes empresas no Brasil, calcada na desigualdade ambiental que faz com que os grupos sociais vulneráveis fiquem com o ônus referente a tais implantações.

$\mathrm{Na}$ busca de uma maior integração com pesquisadores da América Latina contamos com a participação de Vanessa Victoria Humacata da Argentina com o artigo Una perspectiva sociológica de la capacitación docente en Educación Ambiental: un dispositivo de escolarización neoliberal, no qual a autora apresenta a partir da noção conceitual de "educação" os fatores que influenciam na definição das políticas de formação de professores de educação ambiental o atual contexto do neoliberalismo e das reformas educacionais, como na formação de professores na Argentina .

Nicolas Montecinos, do Chile, contribuiu também com essa edição com o artigo ¿Cómo a partir de un movimiento social, surge la revitalización de la Identidad-Territorial dentro de una comunidad? problematizando como a reorganização das comunidades e a reapropriação de identidade - Lafkenche em uma área costeira do sul do Chile, a partir de um movimento de resistência territorial ambiental-, a partir da chegada da empresa multinacional de celulose Arauco y Constitución (Celco, atualmente sob o nome de Arauco ). Ele procurou descrever os processos sociais relativos à ameaça ambiental, social, econômica e cultural que representa para os habitantes deste território o estabelecimento dessa empresa.

No artigo A trama científica e jurídica na construção do Certificado de Agroflorestas de Matheus Sehn Korting aborda o desenvolvimento da trama científica e jurídica formada em torno do Certificado de Agroflorestas, desde as origens do termo e a transformação do conceito por instituições científicas. Também será demonstrado o aparato jurídico que 
subsidia as políticas ambientais desde a Constituição Federal e seus princípios a legislações infraconstitucionais em direção aos licenciamentos florestais.

A seguir Rachel Souza Martins em Ambientalismo e Sustentabilidade: um olhar sobre o discurso ambiental aborda a ideia da construção de uma "socionatureza" como o ponto de partida para as discussões acerca da questão ambiental sob um viés filosófico e antropológico. Ao longo do trabalho a autora tece críticas ao modo como o discurso ambiental se constituiu ao longo da história da humanidade, alicerçando os valores que atribuímos à natureza. Ainda, em um segundo momento discute o surgimento dos movimentos ambientalistas e a importância destes para a construção de uma visão social acerca da natureza, introduzindo também os debates sobre os temas da justiça social e ambiental como questões para a ampliação do discurso ético e ambiental.

No artigo Conflito ambiental relacionado a processos especulativos e imobiliários no Pontal da Barra, Pelotas/RS de Gitana Cardoso da Silveira Nebel são explicitadas as controvérsias entre atores sociais com distintos modos de significação, uso e apropriação territorial no contexto de conflito ambiental em torno do Pontal da Barra, Laranjal, Pelotas/RS. Para isso, a autora a partir do conflito trouxe à tona diferentes atores sociais, contemplando suas visões, posições, interesses, discursos e estratégias de disputa e legitimação no campo ambiental problematizando o modelo dominante e hegemônico de “desenvolvimento" na região que denotam certas posturas de homogeneização e exclusão silenciando as controvérsias públicas.

Maria Angélica Maciel Costa no trabalho A questão hídrica na metrópole fluminense: um olhar sob a dinâmica da gestão (dita) participativa analisa a relação entre, por um lado, os discursos e as formas institucionais que têm por pressuposto formal a igualdade jurídica no acesso à água e, por outro, as práticas concretas do conjunto de atores sociais envolvidos nos embates e debates relativos à gestão dos recursos hídricos. A água foi um ponto de entrada para a discussão das questões de inserção social, eficácia de políticas públicas e compromissos governamentais. Através de técnicas e métodos qualitativos de pesquisa, especialmente a etnografia institucional foi analisada a dinâmica da gestão dita participativa de águas na metrópole fluminense, através do caso da atuação do Comitê de Bacia Hidrográfica da Baía de Guanabara (CBH Guanabara) e a desigualdade no acesso à água da metrópole, assim como aos próprios sistemas de decisão que regulam tal acesso. 
Abordando uma questão pública atual e que é atualmente um grave problema de saúde pública e questão ambiental Maciel Cover e Patrícia Silveira Rodrigues no trabalho "Uma análise sobre a "Campanha Permanente Contra os Agrotóxicos e pela vida" tratam de um conjunto de ações com o intuito de chamar a atenção para a sociedade brasileira diante do eminente risco que estes produtos químicos acarretam para a saúde humana e para o meio ambiente. Fundamentados nas discussões sobre sociedade global de risco o autor e a autora refletem sobre a campanha a partir da seguinte questão: que fatores podem ser mobilizados para explicar o crescimento em termos organizativos da Campanha Permanente contra os Agrotóxicos e pela Vida?

Tratando sobre o tema dos Povos e Comunidades Tradicionais no artigo A Tensão Intrínseca à Proteção e à Manutenção do Território Comunitário em Formas Não Convencionais de Organização: Os Faxinais, Antônio João Hocayen da Silva, Fabio Vizeu e Rene Eugenio Seifert busca compreender a tensão entre racionalidade substantiva e racionalidade instrumental nas Comunidades Tradicionais de Faxinais do Paraná, onde os pressupostos de desenvolvimento, de crescimento e de progresso conflitam com a percepção e o significado de convívio coletivo e de uso comunitário do território atribuído aos faxinalenses. Considerando-se a realidade investigada, eles perceberam a manifestação da tensão intrínseca à proteção e à manutenção do território comunitário, atrelada ao discurso da mobilização e resistência a partir do contributo sociológico de Guerreiro Ramos (1989).

Sob essa perspectiva, João Augusto de Andrade Neto, no trabalho Populações tradicionais: Identidades, meio ambiente e conflitos fundiários, abordou a questão da visibilização de conflitos envolvendo o acesso à terra e a outros recursos naturais, nos quais a categoria "populações tradicionais" ganham crescente destaque, indicando a existência de grupos que assumem identidades como quilombolas, indígenas, ribeirinhos, quebradeiras de coco babaçu, faxinais, fundo de pasto, dentre outras denominações. Além das questões ambientais e culturais que apontam para particularidades de cada um desses grupos específicos, é possível identificar um traço comum a várias situações distintas de conflitos sociais envolvendo "populações tradicionais": a disputa fundiária envolvendo os territórios historicamente ocupados por tais grupos. Em uma abordagem histórica o autor discute elementos que permitem discutir a relação entre a identidade de grupos presentes no chamado mundo rural brasileiro, conhecidos como "populações tradicionais", e o lugar dos conflitos sociais vivenciados por esses segmentos em meio ao secular problema fundiário no país. 
NORUS - v3, n.4, jul - dez 2015.

Por fim, é apresentada uma entrevista realizada com Nilo Schiavon, agricultor familiar que mora na Colônia São Manoel, em Pelotas, RS, que foi um dos fundadores da Associação dos Pequenos Agricultores Agroecologistas da Região Sul (ARPA-SUL) e também apoiador da Cooperativa Sul Ecológica formada em setembro de 1995. Nessa entrevista ele relatou a experiência de se sentir "na contramão do mundo", que significou se posicionar de modo contrário ao amplo processo de modernização técnica da agricultura, que implicava em seguir preceitos e receituários que levavam à intensificação da produtividade e ao uso de alto grau de insumos externos para continuidade da produção. Ao longo da entrevista é abordado esse processo e também a questão dos agrotóxicos.

Os trabalhos deste dossiê apresentam diferentes perspectivas teórico-metodológicas em que aspectos sociais e científicos se entrecruzam no debate público. É com satisfação que publicamos esse conjunto de trabalhos e pesquisas na Revista Novos Rumos Sociológicos (NORUS) do Programa de Pós-Graduação em Sociologia (PPGS) da Universidade Federal de Pelotas (UFPel), em seu quarto número.

Desejamos a todos (as) uma ótima leitura e reflexão!

\section{REFERÊNCIAS BIBLIOGRÁFICAS}

BECK, U. Risk Society. Towards a New Modernity. London: Sage Publications, 1992.

BUTTEL, Frederick H. A sociologia e o meio ambiente: um caminho tortuoso rumo à ecologia humana. Perspectivas, São Paulo, n. 15, p. 69-94. 1992.

CASTELLS, Manuel. O poder da identidade. $3^{\text {a }}$ ed. São Paulo: Paz e Terra. 2002.

CASADO, G. G.; SEVILLA-GUZMÁN, E.; MOLINA, M. G. São Paulo, São Paulo, v. 51, n. 2, p. 37-56, jul./dez. 2004. Introducción a la agroecología como desarrollo rural sostenible. Madrid: Mundi-Prensa, 2000.

GIDDENS, Anthony. As consequências da modernidade. São Paulo: Ed. UNESP, 1991.

GIDDENS, Anthony. Risco, Confiança, Reflexividade. In: BECK, U.; GIDDENS, A.; LASH, S. (eds). Modernização Reflexiva. São Paulo: Ed. UNESP, 1997. 
Apresentação Dossiê Questão ambiental e movimentos socioambientais

HABERMAS, Jürgen. A nova intransparência. A crise do Estado de bem-estar social e o esgotamento das energias utópicas. Novos Estudos CEBRAP. São Paulo, nº18:103-114, setembro, 1987.

Teoria do agir comunicativo. São Paulo: Martins Fontes, 2012.

TOURAINE, Alain. Pensar outramente: O discurso interpretativo dominante. Petrópolis: Vozes, 2009. 